\title{
Turismo e participação social na gestão do Centro Histórico de Salvador (BA) ${ }^{1}$
}

\author{
Tourism and social participation in the management of the Historic Center of \\ Salvador (BA)
}

Júlia Erminia Riscado[a] (1)

[a] Universidade Federal Fluminense (UFF), Instituto de Ciências Humanas e Filosofia, Departamento de Ciência Política, Niterói, RJ, Brasil

Como citar: Riscado, J. E. (2019). Turismo e participação social na gestão do Centro Histórico de Salvador (BA). urbe. Revista Brasileira de Gestão Urbana, 11, e20180026. https://doi.org/10.1590/2175-3369.011.e20180026

\section{Resumo}

Cada vez mais próximo a setores empresariais, o turismo tem se tornado alvo de recorrentes críticas por se distanciar de setores sociais na elaboração e no acompanhamento de políticas públicas e/ou programas de recuperação de centros históricos, principalmente em áreas urbanas. Com base em recomendações internacionais, projetos de âmbito nacional, jornais e observação direta, o presente artigo tem como objetivo avaliar os impactos da atividade turística nos projetos para o Centro Histórico de Salvador, na Bahia. A primeira parte do texto tratará do reconhecimento do turismo como instrumento de difusão e de sustentabilidade para zonas históricas urbanas por meio de normativas internacionais e iniciativas de âmbito nacional. Posteriormente, será observado como tais dispositivos normativos e legais foram incorporados às ações de desenvolvimento turístico e aos projetos de revitalização no Centro Histórico de Salvador. Espera-se, com isso, contribuir para estudos urbanos e demais pesquisas que tratem da gestão participativa em áreas históricas e de intensa atividade turística.

Palavras-chave: Centros históricos. Turismo. Gestão participativa.

\section{Abstract}

Increasingly close to business sectors, tourism has become the target of recurrent criticism for distancing from social sectors during designing and monitoring public policies and/or programs to restore historic centers, especially in urban areas. Based on international recommendations, national projects, newspapers and direct observation, this article aims to evaluate the impacts of tourist activity in Salvador historic center preservation and revitalization projects. The first part of the text will deal with the recognition of tourism as an instrument of diffusion and sustainability for urban historical zones through international regulations and national initiatives. Subsequently, it will be observed how such normative and legal devices were incorporated in the actions of tourist development and revitalization projects in the historical center

${ }^{1}$ O presente trabalho foi realizado com apoio da Coordenação de Aperfeiçoamento de Pessoal de Nível Superior - Brasil (CAPES).

JER é bacharela e licenciada em História, mestra em História, doutoranda em Ciência Política, e-mail: julia_riscado@yahoo.com.br 
of Salvador, Bahia. Therefore, it is expected to contribute to urban studies and other research that deal with participative management in historical areas and intense tourism activity.

Keywords: Historic centers. Tourism. Participative management.

\section{Introdução}

A cidade contemporânea, configurada por espaços de conflitos e de constante negociação entre diversos interesses, reflete a inconstância do momento vivido. 0 surgimento progressivo de novas linguagens e de espaços alternativos em qualquer ação de defesa e valorização dos legados físicos do passado representa um imperativo para as sociedades contemporâneas e um desafio para os territórios.

Nesse sentido, o processo de ressignificação do passado torna-se fundamental para a compreensão do papel dos centros históricos no contexto de desenvolvimento urbano recente. A promoção do patrimônio nesses espaços, quase sempre vinculada a uma lógica empresarial, converte a marca de tradição do patrimônio em capital de inovação.

A partir da visibilidade seletiva de elementos emblemáticos das zonas urbanas antigas, o turismo passou a ser elemento fundamental para a competitividade entre cidades ao explorar suas vantagens específicas, estimulando novas atrações de consumo e entretenimento. A postura empreendedora adotada por administrações nacionais e locais, em parceria com agentes privados, tornou-se um modelo de desenvolvimento urbano compartilhado nas mais diferentes realidades ao redor do mundo (Harvey, 2005; Peixoto, 2003).

Em uma perspectiva crítica, entretanto, o turismo passa a ser considerado um setor que homogeneíza os centros históricos, contaminando negativamente sua cultura, sua economia e sua arquitetura (Carrión, 2005; Choay, 2002; Peixoto, 2003). Um dos efeitos imediatos desse processo é a estetização das práticas cotidianas dos indivíduos e dos locais que caracterizam o dia a dia dos núcleos urbanos centrais. Quando recebem o status de produto ou de imagem a ser consumida, os centros históricos adentram em um ciclo de iniciativas urbanísticas que prioriza o embelezamento de fachadas e estimula a criação de eventos atrativos que combinam o tradicional com o festivo.

Ao priorizar um estilo de vida a ser vendido para turistas, os projetos de recuperação e de revitalização se distanciam dos indivíduos da cidade. Deixam de exercer sua centralidade simbólica enquanto espaços de encontros e de convívio das diferenças para se transformarem em espaços cenográficos (Baptista \& Pujadas, 2000; Choay, 2002). Tal dissonância amplia o questionamento sobre as políticas e os programas aplicados nos centros históricos.

Com base no cenário apresentado, este artigo propõe uma avaliação acerca dos impactos do turismo na gestão de centros históricos. A primeira parte do texto abordará a inclusão do turismo como instrumento de difusão e de sustentabilidade para zonas históricas urbanas por meio de normativas internacionais e iniciativas de âmbito nacional. Posteriormente, será observado como tais dispositivos normativos e legais foram incorporados às ações de desenvolvimento turístico e de revitalização no Centro Histórico de Salvador, na Bahia. Espera-se, com isso, contribuir para estudos urbanos e demais pesquisas que tratem da gestão participativa em áreas históricas e de intensa atividade turística.

\section{O turismo como instrumento de acesso e difusão do patrimônio urbano}

Na década de 1960, o tema do turismo recebeu destaque na relação entre desenvolvimento socioeconômico e preservação do patrimônio. Diante dos avanços da industrialização e da urbanização desordenada, a atividade turística surgiu como uma possibilidade de conciliar os interesses desenvolvimentistas com a preservação do patrimônio ambiental, cultural e histórico.

Em 1967, como consequência da Reunião sobre Conservação e Utilização dos Monumentos e Sítios de Interesse Histórico e Artístico da Organização dos Estados Americanos (OEA), produziu-se um conjunto 
de recomendações denominado Normas de Quito. Seu intuito foi oferecer propostas de utilização do acervo patrimonial latino-americano, que sofria com o abandono e a deterioração, para o incremento econômico em áreas de poucos recursos (OEA, 1967).

Nesse momento, ampliou-se a responsabilidade atribuída aos governos nacionais e locais de estabelecer medidas de proteção que valorizassem o patrimônio cultural e, ao mesmo tempo, trouxessem benefícios econômicos por meio de investimentos da iniciativa privada e do desenvolvimento turístico nas regiões. Percebe-se a contribuição dos debates internacionais na elaboração de estratégias adotadas pelas nações a fim de compatibilizar o desenvolvimento econômico, a preservação do patrimônio e o turismo.

No Brasil, essa influência pode ser notada pelos diálogos e acordos de cooperação estabelecidos entre DPHAN ${ }^{2}$ e UNESCO na década de 1960. Em 1964, a pedido da UNESCO, o então diretor do Real Instituto de Estudo e Conservação do Patrimônio Artístico em Bruxelas, Paul Coremans, veio ao Brasil estabelecer as bases de ação para a cooperação entre o país e o organismo. 0 objetivo da missão seria oferecer assistência técnica com ênfase nas áreas de turismo e preservação do patrimônio cultural.

Entre os programas desenvolvidos na época, o Programa Turismo Cultural ${ }^{3}$ tornou-se o mais representativo para compreender esse movimento convergente entre as instâncias nacional e internacional no que se refere ao estabelecimento de estratégias de aproximação de ações de preservação do patrimônio urbano e desenvolvimento turístico. Além de Coremans, outras iniciativas merecem destaque, como as coordenadas pelo inspetor do Serviço Principal de Inspeção dos Monumentos e de Inspeção de Sítios na França, Michel Parent. Durante sua atuação, foram avaliados sítios e bens já protegidos pelo DPHAN em 35 cidades nos anos de 1966 e 1967 (Leal, 2008).

Os apontamentos de Michel Parent constituiriam a base de toda a atuação futura não só do IPHAN, mas de todo o governo federal com relação ao patrimônio cultural, histórico e natural brasileiro. Embora tenha mantido o planejamento urbanístico sob uma perspectiva centralizada, em seus relatórios foram valorizadas as potencialidades e a infraestrutura turísticas de cada região.

A gestão do patrimônio urbano e a sua relação com o turismo foram tratadas novamente na Convenção do Patrimônio Mundial de 1972, que instituiu o conceito de patrimônio da humanidade. A adesão superior a 90\% dos países-membros da UNESCO (ou associados a ela) à Convenção explica, ainda hoje, o impacto e a relevância da designação de bens para a classificação de patrimônio da humanidade.

Ao estabelecer uma nova categoria aos processos de patrimonialização, a Convenção de 1972 ratificou o entendimento de que a salvaguarda do patrimônio cultural deveria estar relacionada à cooperação cultural internacional. Ainda que o patrimônio cultural material ou imaterial fosse resultado de uma expressão particular referente a uma sociedade, sua representatividade atingiria toda a comunidade internacional por exemplificar a capacidade criativa e a diversidade cultural inerente a todos os povos.

Houve ainda, por parte da UNESCO, a preocupação de estabelecer critérios que servissem de respaldo teórico na elaboração de políticas de preservação do patrimônio cultural e natural pela comunidade internacional. Para isso, foi adotada uma "[...] metodologia programática, baseada no sistema de listas e no uso de diretrizes operacionais para sua execução" (Sampson et al., 2010, p. 31). Diante de sua abrangência, a Convenção de 1972 tornou-se um parâmetro para a gestão do patrimônio na atualidade.

Alguns anos depois, o Seminário Internacional de Turismo Contemporâneo e Humanismo produziu a Carta do Turismo Cultural, na qual procurou destacar a articulação entre preservação do patrimônio e turismo cultural, visando ao desenvolvimento socioeconômico em regiões históricas. Diferentemente da perspectiva adotada na década anterior, a Carta do Turismo Cultural apresentou preocupações acerca dos impactos negativos das atividades turísticas sobre o patrimônio cultural e natural. Entretanto, o

\footnotetext{
2 Criado em 1946, o Departamento do Patrimônio Histórico e Artístico Nacional (DPHAN) foi transformado em Instituto do Patrimônio Histórico e Artístico Nacional (IPHAN) em 1970.

${ }^{3}$ Ao longo da década de 1960, a UNESCO reconheceu a necessidade de investir no turismo com a finalidade de atrair mais incentivos financeiros para a conservação e a valorização de monumentos e sítios históricos. Com isso, a partir da Conferência Geral da UNESCO de 1966, instituiu-se uma política específica para o turismo cultural, na qual ficou estabelecido que caberia à organização prestar auxílio aos países-membros no estudo e na execução de programas de salvaguarda, contribuindo para a valorização de sítios e monumentos que possuíssem algum vínculo com o desenvolvimento do turismo (UNESCO, 1969).
} 
turismo cultural continuava a ser compreendido como a atividade mais adequada à intenção de proteção de bens culturais:

0 turismo cultural é aquela forma de turismo que tem por objetivo, entre outros fins, o conhecimento de monumentos e sítios histórico-artísticos. Exerce um efeito realmente positivo sobre estes tanto quanto contribui - para satisfazer seus próprios fins - a sua manutenção e proteção. Esta forma de turismo justifica, de fato, os esforços que tal manutenção e proteção exigem da comunidade humana, devido aos benefícios socioculturais e econômicos que comporta para toda a população implicada (ICOMOS, 1976, p. 2).

No mesmo ano, a 19a Conferência Geral da UNESCO produziu a Recomendação de Nairóbi, que se voltou à salvaguarda de conjuntos históricos e sua função na vida contemporânea. De acordo com o documento, eram considerados conjuntos históricos “[...] os sítios pré-históricos, as cidades históricas, os bairros urbanos antigos, as aldeias e os lugarejos, assim como os conjuntos monumentais homogêneos" (UNESCO, 1976, p 3). Tal definição se apresentou atrelada à noção de ambiência, o que instituiu uma percepção dinâmica sobre esses espaços e os laços sociais, econômicos e culturais ali construídos.

Nesse sentido, a Recomendação de Nairóbi identificou nos processos de proteção dos conjuntos históricos a necessidade de respeitar as funções existentes naquelas áreas, como comércio e artesanato, por serem compatíveis com o contexto social, econômico, urbano e cultural em que estariam inseridas. Cabe destacar, contudo, que não foi proposta uma cristalização dessas atividades, mas sua valorização e sua utilização enquanto mecanismos de desenvolvimento socioeconômico para as comunidades locais.

Assim como a Carta do Turismo Cultural, a Recomendação de Nairóbi reconheceu a importância das comunidades locais enquanto agentes nas ações de proteção e sustentabilidade do patrimônio cultural. Entretanto, no último documento, houve maior preocupação com o estabelecimento de ações conjuntas entre administrações regionais, locais e nacionais a fim de orientar e financiar moradores e empreendedores locais.

No Brasil, essas ideias foram assimiladas em iniciativas, como o Programa Integrado de Reconstrução de Cidades Históricas do Nordeste ${ }^{4}(\mathrm{PCH})$, marco na recuperação do patrimônio urbano brasileiro. Implementado e coordenado pelo Ministério do Planejamento e Coordenação Geral ${ }^{5}$ em 1973, o objetivo principal do PCH era o "[...] desenvolvimento econômico do Nordeste por meio da atividade turística, tendo como principal capital o patrimônio cultural” (Correa \& Faria, 2011, p. 25).

Influenciado tanto pelas recomendações internacionais quanto pelos Encontros de Governadores de Brasília, em 1970, e de Salvador, em 1971, o PCH propôs um desenvolvimento econômico e social regional por meio do aproveitamento do patrimônio cultural urbano pelo turismo. É preciso ressaltar ainda o projeto político que se configurava naquele momento. Sob a gestão de Emílio Médici, o PCH foi criado mediante a implementação do I Plano Nacional de Desenvolvimento (1972-1974), que adotou uma lógica econômica marcadamente centralizadora e tecnocrática (Azevedo, 2016).

As divergências internas sobre a condução da economia em um cenário internacional cada vez mais delicado e as particularidades político-institucionais dos governos nas três esferas de poder contribuíram para a extinção do programa em 1979. Ademais, com a nomeação de Eduardo Portela para o Ministério da Educação e Cultura, a política cultural passou a adotar uma perspectiva mais inclusiva sobre a gestão do patrimônio cultural, explorando a participação da sociedade nesse processo (Azevedo, 2016).

Essa tendência ficou mais evidente com o processo de redemocratização e, posteriormente, com a elaboração da Constituição de 1988, que procurou restaurar a federação e consolidar a participação democrática de seus cidadãos. No campo da preservação do patrimônio, essa mudança de perspectiva pôde ser percebida na ampliação do conceito de patrimônio estabelecido no Decreto-lei no 25, de 30 de novembro de 1937, além do próprio texto constitucional, como é possível observar no conteúdo do artigo 216 :

\footnotetext{
${ }^{4}$ Criado em 1973, o programa foi posteriormente estendido a todo o país recebendo o nome de Programa Cidades Históricas.

${ }^{5}$ Lei no 6.036, de 1o de maio de 1974, que criou a Secretaria de Planejamento (SEPLAN), com status de Ministério, ligada à Presidência da República, passando a ser o centro das decisões econômicas do país.
} 
Art. 216. Constituem patrimônio cultural brasileiro os bens de natureza material e imaterial, tomados individualmente ou em conjunto, portadores de referência à identidade, à ação, à memória dos diferentes grupos formadores da sociedade brasileira, nos quais se incluem: I) as formas de expressão; II) os modos de criar, fazer e viver; III) as criações científicas, artísticas e tecnológicas; IV) as obras, objetos, documentos, edificações e demais espaços destinados às manifestações culturais; V) os conjuntos urbanos e sítios de valor histórico, paisagístico, artístico, arqueológico, paleontológico, ecológico e científico (Brasil, 1988).

O alargamento da noção de patrimônio abriu caminho para um processo de descentralização dos programas e dos projetos de preservação nas demais esferas de poder que atuariam em parceria com as comunidades locais:

§1ํ- - O Poder Público, com a colaboração da comunidade, promoverá e protegerá o patrimônio cultural brasileiro, por meio de inventários, registros, vigilância, tombamento e desapropriação, e de outras formas de acautelamento e preservação (Brasil, 1988).

No texto constitucional, procurou-se incorporar, de modo sucinto, um debate iniciado décadas antes por grupos de intelectuais e técnicos do país. Com o impacto desenvolvimentista, que caracterizou os anos 1950 e 1960, e o crescimento da população urbana, houve a necessidade de ampliar o alcance das políticas de preservação.

A atenção ao desenvolvimento local, a atividade turística e a gestão do patrimônio estimularam a criação de iniciativas, como o seminário promovido pelo Programa Nacional de Recuperação e Revitalização de Núcleos Históricos' ${ }^{6}$ em 1986, em Salvador. Influenciado pelo clima e pelos ideais que fundamentaram a Constituição Federal, o seminário se mostrou uma tentativa inicial de introduzir uma lógica participativa à gestão dos centros históricos.

Todavia, os conflitos de interesses, tanto entre técnicos e representantes da sociedade civil quanto entre os presentes no interior desses grupos, suplantaram o objetivo principal do empreendimento. A proposta de gestão para o Centro Histórico de Salvador se consolidou anos mais tarde, com o modelo de revitalização baseado na noção de city marketing ${ }^{7}$.

Durante a década de 1990, as políticas de preservação do patrimônio passaram a utilizar estratégias de promoção e de marketing visando ao desenvolvimento econômico e à atração de investimentos privados. Os centros históricos deixariam de refletir seus significados simbólicos, representativos para a população residente, para dar lugar à valorização da estética de fachadas e monumentos.

Com a intensificação das críticas aos modelos de recuperação urbana adotada nos anos 1990 por parte de acadêmicos, agentes públicos e atores sociais, houve um retorno às questões de ordem social, como geração de empregos e conversão de estabelecimentos públicos em espaços para o atendimento social. Essa reorientação trouxe um novo perfil às propostas de gestão de centros históricos, que agora buscavam aliar atratividade turística às demandas de moradores e comerciantes da região, como habitação, atividades sociais e desenvolvimento econômico local.

\section{A trajetória de ações na região histórica de Salvador}

Diante de um cenário nacional marcado pelos efeitos da industrialização, do crescimento urbano e das políticas desenvolvimentistas, a região histórica de Salvador promoveu, ao longo da década de 1960, importantes iniciativas de identificação, valorização e proteção do patrimônio, como o Programa Turismo Cultural (já mencionado).

\footnotetext{
6 O Programa Nacional de Recuperação e Revitalização de Núcleos Históricos foi uma iniciativa federal que procurou, a partir da cooperação técnica celebrada entre o Ministério da Cultura e o Ministério do Desenvolvimento Urbano, implementar modelos de gestão participativa do patrimônio artístico e cultural em prefeituras, como em Olinda e Salvador, e governos estaduais.

70 termo "city marketing" constitui-se na orientação da política urbana à criação ou ao atendimento das necessidades do consumidor, seja ele empresário, turista ou o próprio cidadão. Corresponde à promoção de uma cidade, afetando os seus habitantes e atraindo eventuais investidores, na busca de construir uma nova imagem.
} 
Nesse programa, destacou-se a atuação do inspetor Michel Parent, técnico do Serviço Principal de Inspeção dos Monumentos e de Inspeção de Sítios na França, entre os anos de 1966 e 1967. Durante o período em que esteve no Brasil, foram avaliadas 35 cidades, sendo Salvador um caso que recebeu maior atenção por apresentar "[...] elementos favoráveis que permitem formular bons presságios para a promoção geral do Brasil" (Leal, 2008, p. 87).

Entre os aspectos destacados, Michel Parent ressaltou o potencial econômico da região com o desenvolvimento da indústria petrolífera, que direcionaria $10 \%$ dos royalties recebidos pelo Estado da Bahia para o Departamento da Educação e Cultura. Diferentemente dos demais Estados, observou ainda a disponibilidade administrativa e financeira local em colaborar com as iniciativas propostas pela UNESCO.

A relevância histórica da região foi outro aspecto que recebeu atenção ao longo do estudo. Mesmo se encontrando em aparente decadência, seria possível notar nos bairros antigos de Salvador a influência da arquitetura europeia nos casarios, nas igrejas, nas praças e nas ruas. Essa característica fez o perito francês considerar Salvador como a "[...] primeira cidade de arte do Brasil" (Leal, 2008, p. 88).

Além da herança europeia, a cidade apresentava ainda elementos da cultura afro-americana que não poderiam ser desconsiderados, como o candomblé, a capoeira, o artesanato presente no Mercado Modelo e o trabalho desenvolvido pelo Instituto Afro-Oriental ${ }^{8}$. Diante das múltiplas referências culturais e históricas convivendo harmonicamente, Salvador seria compreendida como a "[...] cidade por excelência onde o Brasil pode testemunhar diante dos visitantes suas culturas específicas" (Leal, 2008, p. 93).

Suas considerações ressaltaram o lugar do turismo como atividade de promoção, desenvolvimento e sustento do patrimônio cultural, convergindo com a política de desenvolvimento adotada pelo país naquele momento, como no caso do Programa Integrado de Reconstrução de Cidades Históricas do Nordeste. Criado em 1973 pelo Ministério do Planejamento e Coordenação Geral, o PCH atuou até o final daquela década com o intuito de promover o desenvolvimento econômico regional por meio da atividade turística, reconhecendo o patrimônio cultural como um principal capital (Correa \& Faria, 2011).

Em 1985, com a entrada do Centro Histórico de Salvador para a lista de bens considerados patrimônio da humanidade pela UNESCO, percebeu-se um esforço entre os diferentes entes federativos em promover ações de proteção e revitalização mais eficientes. Inscrito a partir dos critérios IV e VI, o sítio "Centro Histórico de Salvador da Bahia" foi classificado como patrimônio da humanidade por apresentar uma considerável densidade de monumentos e arquitetura colonial, ao mesmo tempo que mantinha sua relevância nas funções administrativa, comercial, defensiva e residencial. Destacou-se ainda a forte presença de elementos das culturas africana, americana, europeia e indígena, além de seu papel fundamental na história do país e no processo de expansão marítima promovido pelos países europeus entre os séculos XV e XVII.

No ano seguinte, Lina Bo Bardi, em parceria com Marcelo Carvalho Ferraz e Marcelo Suzuki, desenvolveu uma proposta de recuperação para a área. Esse projeto, segundo Marcelo Ferraz, diferenciava-se daqueles implementados anteriormente por ter como foco a preservação da identidade local e a manutenção do perfil dos habitantes locais.

0 "caso" do Centro Histórico de Salvador é: não a preservação de arquiteturas importantes (como seria em Minas), mas a preservação da Alma Popular da Cidade. Em poucas palavras: o plano deve ser "socioeconômico" para não repetir os erros de conhecidos interventos em cidades ilustres como Roma, Bologna, Veneza, e inúmeros maravilhosos recantos do Velho Mundo que mudaram a base social de inteiras regiões, com os moradores de anos e anos jogados longe e média-classe-média, tomando conta. Para evitar isso estamos procurando juntar o trabalho à habitação (é a Idade Média ao contrário) e a um pequeno comércio: uma espécie de economia subterrânea (Ferraz, 1996, p. 270).

\footnotetext{
${ }^{8}$ Criado em 1959 na Universidade Federal da Bahia (UFBA), o atual Centro de Estudos Afro-Orientais tem como objetivo desenvolver estudos asiáticos e africanos, além das linhas e dos grupos de pesquisa que tratam do negro ou das relações raciais no Brasil dentro das estruturas disciplinares existentes (Sociologia, Antropologia e História, em particular).
} 
Dois anos após a elaboração da proposta, a Prefeitura de Salvador instituiu outro projeto: o Parque Histórico do Pelourinho (PHP). Vinculada à Fundação Gregório de Mattos ${ }^{9}$, o PHP tinha como objetivo desenvolver pesquisas, cadastros, levantamentos de dados sobre infraestrutura local, promover a segurança e a limpeza públicas, além de ser responsável pela criação de um calendário de eventos culturais no centro histórico.

Em comum, as iniciativas elaboradas ao longo da década de 1980 imprimiram um novo olhar sobre o Centro Histórico de Salvador, reconhecendo as comunidades locais no processo de proteção da área. Entretanto, o discurso de valorização empreendido pelo PHP dependia da ideia de impulsionar a economia local por meio do turismo, criando uma intensa campanha de marketing na região.

Foi criada uma forma distinta de recuperação dos centros históricos, baseada na utilização dos meios de comunicação e na construção de uma dinâmica econômica específica para a região. No lugar da finalidade residencial e comercial, sobrados e casas do centro histórico transformaram-se em cafés, bares, restaurantes, centros culturais, galerias de arte, espaços para shows, hotéis, pousadas ou albergues, estacionamentos, bancos, livrarias, lojas e sede administrativas de alguns órgãos públicos ligados ao patrimônio artístico-cultural (Braga, 2008).

A nova dinâmica propunha aliar consumo, lazer e cultura na área recuperada. Contudo, a apropriação turística adotada dificultaria a integração com a população residente na área norte do centro histórico e em bairros circunvizinhos. Após a conclusão da primeira etapa do Programa de Recuperação do Centro Histórico de Salvador, iniciado em 1991, foi possível notar a intensificação das tensões presentes entre técnicos, poder público e moradores da região.

$\mathrm{Na}$ etapa de cadastramento dos habitantes da área, foi revelado que pouco mais de $0,2 \%$ era proprietário de seus imóveis. A maioria não tinha direito de posse devido às condições irregulares de sublocação. Sua condição social era percebida no estado de precariedade em que se encontravam as construções da região. Por esse motivo, grande parte dos moradores aceitou a remoção.

Essa situação expôs a fragilidade das medidas empreendidas pelo Instituto do Patrimônio Artístico Cultural da Bahia (IPAC) ${ }^{10}$ e pelo Setor de Planejamento e Pesquisas Sociais. Apesar de atuarem na recuperação do patrimônio cultural e no desenvolvimento socioeconômico da região, tais organizações não conseguiram atender plenamente às comunidades locais, acentuando o processo de gentrificação ainda incipiente.

Tal situação interferiu no perfil social da população e nas manifestações culturais que haviam caracterizado o local e o tornado atrativo turisticamente. Já no início dos anos 2000, foi possível notar uma redução do fluxo turístico na região, o que alertava para a necessidade de mudanças na condução dos processos de intervenção futuros.

A partir de consulta ao acervo do IPAC, foi possível observar como a gestão do Centro Histórico de Salvador é, ainda hoje, uma questão problemática e desafiadora para gestores e técnicos em preservação. Com o intuito de propor uma nova possibilidade de gestão para o centro histórico, foi elaborado e implementado, no ano de 2010, o Plano de Reabilitação Integrado e Participativo do Centro Antigo de Salvador. A partir de um acordo de cooperação técnica entre diversos ministérios do governo federal, o Instituto do Patrimônio Histórico e Artístico Nacional (IPHAN), o Governo do Estado da Bahia e a Prefeitura Municipal de Salvador, pretendeu-se estabelecer diretrizes construídas por meio do diálogo com diferentes setores da sociedade civil.

Com o objetivo de definir e de instituir instrumentos que garantissem a sustentabilidade do centro histórico, o projeto buscou dialogar com aspectos sociais, urbanos e econômicos a fim de tornar a região mais integrada à estrutura urbana que caracteriza a cidade de Salvador. Para isso, foi considerado um recorte territorial mais abrangente do que aquele adotado pelos projetos anteriores.

\footnotetext{
${ }^{9}$ Criada em 1986, a Fundação Gregório de Mattos é um órgão da Prefeitura de Salvador voltado para a gestão de ações culturais na cidade.

${ }^{10}$ Criado em 1967, o IPAC era a autarquia vinculada à Secretaria de Cultura do Estado da Bahia (SECULT), atuando de forma integrada com sociedade civil, administrações municipais e federação na salvaguarda de bens culturais tangíveis e intangíveis e na política pública estadual do patrimônio cultural. A partir de 1980, passou a ser um instituto, seguindo a política federal do IPHAN.
} 
Além do Centro Histórico de Salvador e seu entorno, a área que equivale ao Centro Antigo de Salvador engloba outros dez bairros: Centro, Barris, Tororó, Nazaré, Saúde, Barbalho, Macaúbas, parte do espigão da Liberdade, Comércio e Santo Antônio. Ao incluir mais bairros, esperava-se dar um novo sentido para a localidade que, ao longo dos anos, havia perdido sua funcionalidade e seu interesse econômico. A ideia seria construir proposições para o território por meio da participação efetiva da sociedade civil. Esse processo se deu por meio de três frentes de ação: “[...] a estratégica (político/institucional), a operacional (Escritório de Referência do Centro Antigo de Salvador - ERCAS e UNESCO) e a participativa (Câmaras Temáticas)" (Bahia, 2010, p. 24).

Enquanto a coordenação geral do projeto ficou a cargo da Secretaria de Cultura do Estado da Bahia (SECULT), e seu gerenciamento operacional, do ERCAS, as Câmaras Temáticas atuariam como canais de acompanhamento e consulta de todas as etapas pela sociedade civil. Com o intuito de sistematizar o processo, foram estabelecidas quatro áreas:

CT1- Cultura, Educação, Turismo e Lazer; CT2- Economia, Planejamento, Comércio, Serviços, Emprego e Renda; CT3- Direitos Humanos, Segurança, Cidadania e Justiça; CT4- Habitação, Infraestrutura, Mobilidade e Meio Ambiente (Bahia, 2010, p. 25).

Já na fase de elaboração, houve, por meio de encontros promovidos pelas Câmaras Temáticas, a tentativa de instituir espaços deliberativos que promovessem a participação da sociedade civil nas ações desenvolvidas e na avaliação de produtos. Com uma metodologia participativa, as Câmaras Temáticas atuaram nas etapas seguintes de avaliação de diagnósticos e na análise das ações desenvolvidas pelo ERCAS e das proposições apresentadas por consultores contratados pela UNESCO.

Em 2014, foi elaborado um estudo de avaliação dos primeiros anos do Plano de Reabilitação Participativo para o Centro Antigo. Nele, procurou-se identificar os avanços e os desafios ainda presentes nos procedimentos de intervenção da área. Entre os avanços no processo de implementação identificados, destacou-se o papel do ERCAS na preservação de uma boa imagem do Centro Antigo para os habitantes de Salvador.

De acordo com o relatório, esse instrumento de gestão específico mobilizou cerca de 600 organizações sociais com a finalidade de construir uma nova gestão da área. Nesse sentido, a atuação das Câmaras Temáticas tornou-se fundamental para desenvolver levantamentos técnicos e avaliações das ações empreendidas e promover o debate entre especialistas e comunidades locais (Bahia, 2014).

Todavia, o estudo não avançou muito quanto aos mecanismos de participação social adotados ao longo do desenvolvimento do plano. A presença da sociedade civil ocorreu de modo mais consultivo que propositivo, dificultando sua plena atuação na elaboração de ações de incremento do turismo cultural e nas formas de aproveitamento econômico do patrimônio local, da requalificação do tecido urbano e da apropriação dos equipamentos culturais.

As limitações do projeto recente, embora mais eficaz que as iniciativas anteriores, contribuíram para uma postura mais crítica por parte de algumas organizações sociais, como a Associação de Moradores e Amigos do Centro Histórico de Salvador (AMACH). Criada em 2002 por moradores e beneméritos, a associação buscou orientar ações coletivas de denúncia ao processo de exclusão físico-social pelo qual passavam os habitantes do Centro Histórico de Salvador.

De acordo com a associação, o processo de expulsão dos moradores nessa área teve origem em 1992, quando iniciada a revitalização do conjunto arquitetônico do Centro Histórico de Salvador. Todavia, essa situação teria se intensificado a partir da chamada "poligonal da 7 endereçados recursos do BID, do Programa Monumenta, do Ministério da Cultura e da Companhia de Desenvolvimento Urbano do Estado da Bahia (CONDER).

Embora o Governo do Estado tenha decretado no início de 2002 que os imóveis localizados na área que compõe o Centro Histórico de Salvador se destinariam à execução de empreendimentos habitacionais e comerciais voltados para famílias de baixa renda, a CONDER mantinha o processo de expulsão dos antigos moradores, mesmo aqueles de baixa renda. Assim, a crítica principal da AMACH se fundamenta na ideia de que o patrimônio, tão valorizado pelo imaginário popular e pelo setor turístico, deve ser recuperado em sua plenitude. 
Contudo, seria preciso oferecer meios para garantir a sustentabilidade da população local. Para isso, a mobilização social atuaria no sentido de evitar a contínua evasão de antigos moradores e garantir meios de incluí-los social e culturalmente, além de capacitá-los profissionalmente e conscientizá-los dos direitos e dos deveres em relação ao conjunto urbanístico.

Já a Diretoria do Centro Antigo de Salvador (DIRCAS), vinculada à CONDER, contestou as queixas apresentadas pelos moradores. Segundo declaração do órgão ao jornal $O$ Globo (2015), durante a fase de planejamento do Plano de Requalificação para o Centro Antigo, em 2007, houve a participação de diversas entidades da sociedade civil, entre elas a própria AMACH, a Conferência Nacional dos Bispos do Brasil, o Fórum Municipal para o Desenvolvimento Sustentável do Centro, a Pestana Convento do Carmo, o Projeto Abraço Fraterno e a Universidade Federal da Bahia (UFBA).

\section{Considerações finais}

O presente artigo procurou identificar os impactos da atividade turística nos projetos de proteção e de revitalização para o Centro Histórico de Salvador. Ao longo do texto, observou-se a contribuição de recomendações e de programas internacionais na condução das medidas nacionais de preservação. As Normas de Quito e as missões da UNESCO, por exemplo, foram determinantes para o entendimento da atividade turística como um caminho viável para a garantia de sustentabilidade dos centros históricos brasileiros.

De fato, a emergência de uma economia vinculada ao turismo e ao lazer proporcionou a dinamização e o surgimento de determinadas atividades culturais e econômicas. No caso de Salvador, os projetos de revitalização e desenvolvimento turístico para o centro histórico se mostraram recorrentemente falhos quanto à criação de mecanismos de participação da sociedade civil.

Tendo como alvo principal a atração de eventuais investidores e turistas, esses projetos adotaram estratégias de promoção e de marketing baseadas em uma nova imagem para o centro histórico soteropolitano. Consequentemente, as necessidades da população local ficaram em segundo plano.

Por esse motivo, um dos desafios na gestão do Centro Histórico de Salvador seria ligar o novo ao antigo, retomando um processo de continuidade histórica. Além disso, seria preciso conciliar o atendimento das demandas de uma sociedade industrializada e informatizada com as práticas de preservação da memória, de signos e de práticas representativas a cada um de seus habitantes.

O Plano de Requalificação para o Centro Antigo, elaborado em 2007, reconheceu os diversos aspectos que envolvem a gestão do centro histórico e a necessidade de tratá-los com o mesmo peso. Deve-se ressaltar o papel das Câmaras Temáticas na tentativa de instituir espaços deliberativos capazes de inserir a sociedade civil no monitoramento e na avaliação dos projetos desenvolvidos na região.

Apesar do avanço na gestão de centros históricos, o Plano de Requalificação para o Centro Antigo de Salvador não conseguiu superar o descompasso existente entre os investimentos em turismo e o atendimento às demandas da população local. Nesse sentido, parece correto afirmar que o grande desafio a ser enfrentado pelos gestores públicos ainda é a forma como as propostas serão executadas e perpetuadas no longo prazo.

\section{Referências}

Azevedo, P. (2016). PCH: a preservação do patrimônio cultural e natural como política regional e urbana. Anais do Museu Paulista, 24(1), 237-256. http://dx.doi.org/10.1590/1982-02672016v24n0109.

Bahia. (2010). Centro Antigo de Salvador: Plano de Reabilitação Participativo/Escritório de Referência do Centro Antigo. Salvador: UNESCO.

Bahia. (2014). Plano de reabilitação participativo: avanços (1. ed.). Salvador: CONDER/DIRCAS. 
Baptista, L. V., \& Pujadas, J. J. (2000). Confronto e entre posição: os efeitos da metropolização na vida das cidades. Fórum Sociológico, 3(4), 293-308.

Braga, P. M. (2008). Reabilitação urbana no centro histórico de Salvador: patrimônio cultural, turismo e participação social (Dissertação de mestrado). Faculdade de Arquitetura e Urbanismo, Universidade Católica de Campinas, São Paulo.

Brasil. (1988, 5 de outubro). Constituição da República Federativa do Brasil de 1988. Brasília: Diário Oficial da União. Recuperado em 5 maio de 2016, de http://www.planalto.gov.br/ccivil_03/Constituicao/Constituicao.htm

Carrión, F. (2005). El centro histórico como proyecto y objeto de deseo. Revista Eure, 31(93), 89-100.

Conselho Internacional de Monumentos e Sítios - ICOMOS. (1976). Carta do turismo cultural. Brasília: Iphan. Recuperado em 3 de outubro de 2016, de http://portal.iphan.gov.br/uploads/ckfinder/arquivos/Carta\%20de\%20Turismo\%20Cultural\%201976.pdf Correa, S., \& Faria, R. (2011). O Plano de Cidades Históricas (PCH) no planejamento governamental brasileiro e o desenvolvimento urbano e regional (1973-1979). RISCO: Revista de Pesquisa em Arquitetura e Urbanismo, 14(14), 20-27. http://dx.doi.org/10.11606/issn.1984-4506.v0i14p20-27.

Choay, F. (2002). A alegoria do patrimônio (4. ed.). São Paulo: UNESP.

Ferraz, M. C. (1996). Lina Bo Bardi (2. ed.). São Paulo: Empresa das Artes.

Harvey, D. (2005). Do administrativismo ao empreendedorismo: a formação da governança urbana no capitalismo tardio. In D. Harvey (Ed.), A produção capitalista do espaço (pp. 163-190). São Paulo: Annablume.

Leal, C. (2008). As missões da UNESCO no Brasil: Michel Parent. Rio de Janeiro: IPHAN.

O Globo. (2015, 30 de julho). Com queixas de décadas, moradores esperam reformas no Centro Antigo. Recuperado 23 de agosto de 2016, de http://g1.globo.com/bahia/noticia/2015/07/com-queixas-de-decadas-moradoresesperam-reabilitacao-do-centro-antigo.html

Organização dos Estados Americanos - OEA. (1967). Normas de Quito. Brasília: Iphan. Recuperado em 11 de março de 2017, de http://portal.iphan.gov.br/uploads/ckfinder/arquivos/Normas\%20de\%20Quito\%201967.pdf

Organización de las Naciones Unidas para la Educación, la Ciencia y la Cultura - UNESCO. (1969). La protección del patrimonio cultural de la humanidad: lugares y monumentos. Paris: UNESCO. Recuperado em 2 de setembro de 2016, de http://unesdoc.unesco.org/images/0013/001313/131334so.pdf

Organización de las Naciones Unidas para la Educación, la Ciencia y la Cultura - UNESCO. (1976). Recomendação de Nairóbi. Paris: UNESCO. Recuperado em 1 de outubro de 2017, de

http://portal.iphan.gov.br/uploads/ckfinder/arquivos/Recomendacao\%20de\%20Nairobi

Peixoto, P. (2003). Centros históricos e sustentabilidade cultural das cidades. In Anais do Seminário "A Cidade entre Projectos e Políticas" (pp. 211-226). Porto: Faculdade de Letras, Universidade do Porto. Recuperado em 10 de março de 2017, de http://ler.letras.up.pt/uploads/ficheiros/artigo8511.pdf

Sampson, F., Treves-Habar, J., \& Millward, M. (2010). Informe Mundial de la UNESCO: invertir en la diversidad cultural y el diálogo. Paris: UNESCO.

Editor: Rodrigo Firmino

Recebido: Jan. 31, 2018

Aprovado: Nov. 01, 2018 